\title{
DERMATITIS FROM \\ THE PINE PROCESSIONARY CATERPILLAR
}

\author{
Major D. E. BRADFORD, M.B., Ch.B., M.R.C.P.(Ed.), D.T.M\&H., R.A.M.C.
}

British Military Hospital, Hong Kong

SUMMARY: Contact with the pine processionary caterpillar (Thaumetopaea wilkinsoni larve) and its nest causes an intensely irritant rash. The caterpillar is found in the base areas in Cyprus and cases of dermititis are not uncommon there during the months of February, March and April each year. The skin manifestation, after contact with the caterpillar, and the response to treatment are described.

\section{Introduction}

More than 50 species of caterpillar possess urticating hairs (Herms and James 1961). When describing an outbreak of caterpillar dermatitis Hellier and Warin (1967) identified as causative, in producing a rash, the yellow tail moth caterpillar (Euproctis similis) the small egger moth caterpillar (Eriogaster lanestris) the garden tiger moth caterpillar (Arctia caja) and the oak egger moth caterpillar (Lasiocampa quercus). Others include the Brown tail moth caterpillar (Euoproctis chrysornhoea) (Smith 1966), the puss moth caterpillar (Megalopyge opercularis) the white moth caterpillar (Lagoa crispata) the io moth caterpillar (Autemeris io) and the tussock moth caterpillar (Hemerocampa leucostigma) (McMillan and Purcell 1964).

Pine processionary caterpillar dermatitis has been identified in the Lebanon (Davis 1947) and in Cyprus previously (Cheverton 1936). This paper illustrates the moth and caterpillar concerned (Thaumetopoea wilkinsoni) and describes the effects following deliberate contact with the caterpillar.

\section{The caterpillar}

The adult moth (Fig. 1) emerges during the period August to October. There are five larvae instars, the eggs being laid in October. The nests vary from about 4 to 12 inches and are conical with the apex hanging free (Fig. 2). When the larvae migrate from the nest they tend to do so nose to tail in a long procession and Figure 3 shows such a procession 'forming-up'. On this photograph the urticating hairs are easily seen.

When examining the nests and the caterpillars care was taken to wear plastic gloves and handle the insect with forceps. However in spite of these precautions it was soon obvious that hairs were being disturbed, liberated into the air and causing irritation mainly round the wrists, where they were being caught between skin and cuff, and similarly round the collar area. Figure 4 shows the authors left forearm with developing erythema from further contact due to pulling up the sleeve to scratch round the wrist (the central healing lesion was produced five days prior to the photograph by a similar experiment).

\section{The rash}

Using this powerful skin irritant an attempt was then made to observe the rash in all its stages. Taking a large expanse of normal skin (Fig. 5) two caterpillars were gently brushed across areas about 2 inches across and separated by 3 inches of untouched skin. 


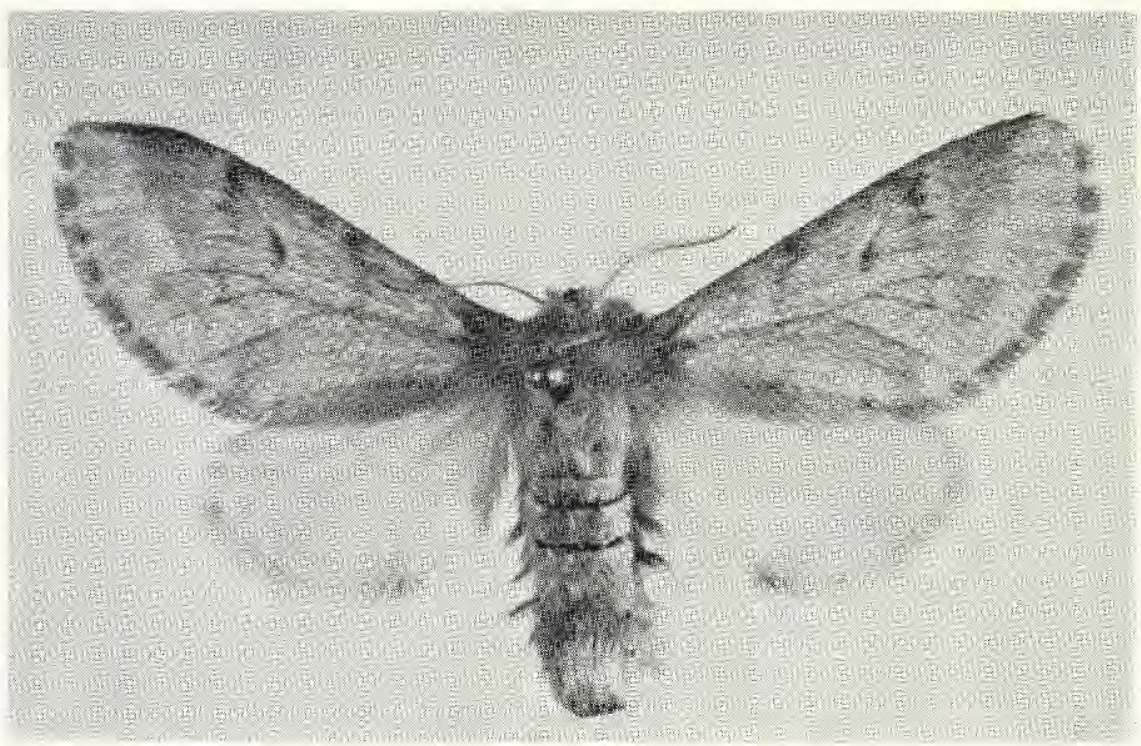

Fig. 1. Pine processionary moth-Thaumetapoea wilkinsoni.

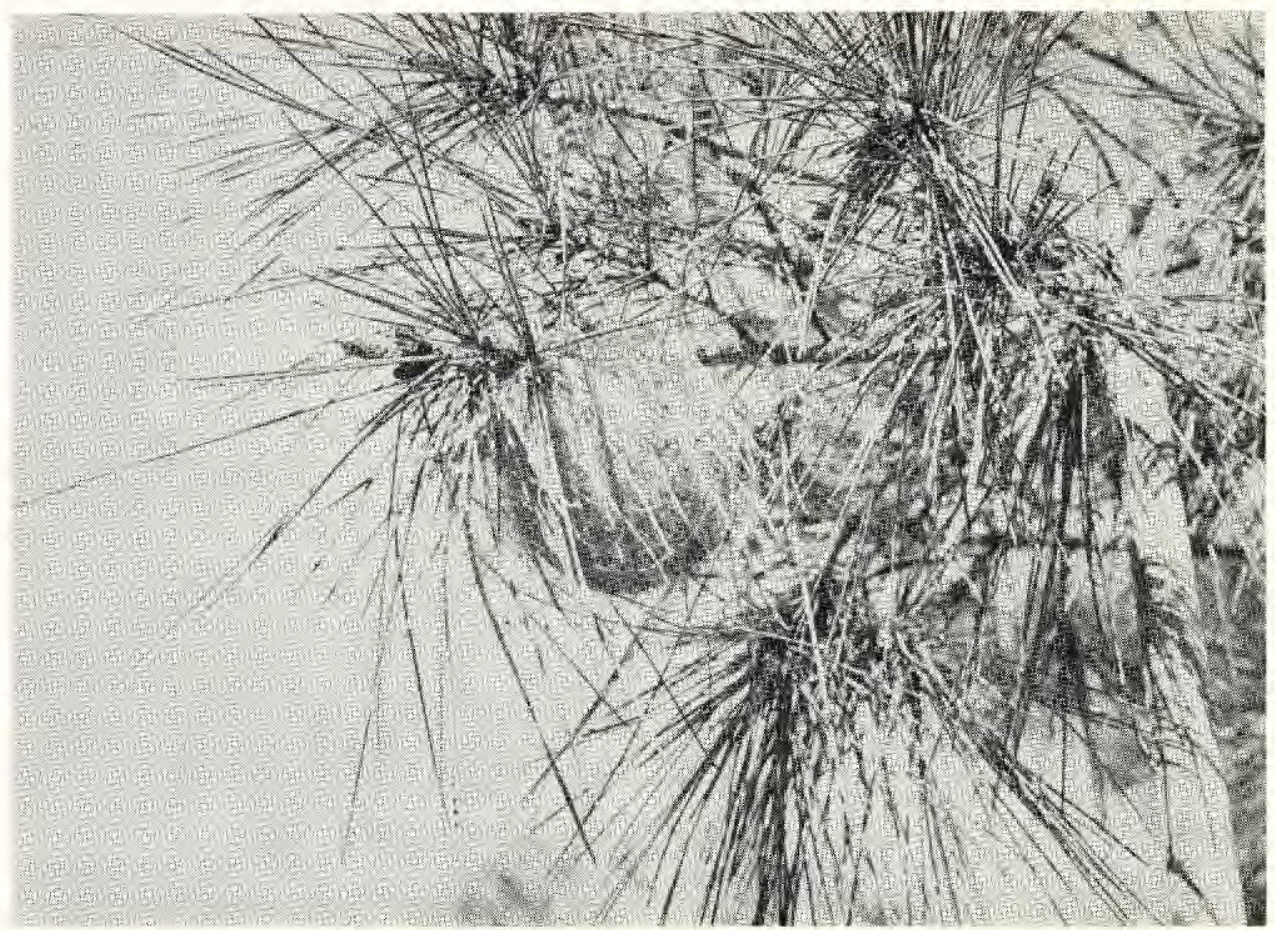

Fig, 2. Nest of pine processionary caterpillar. 


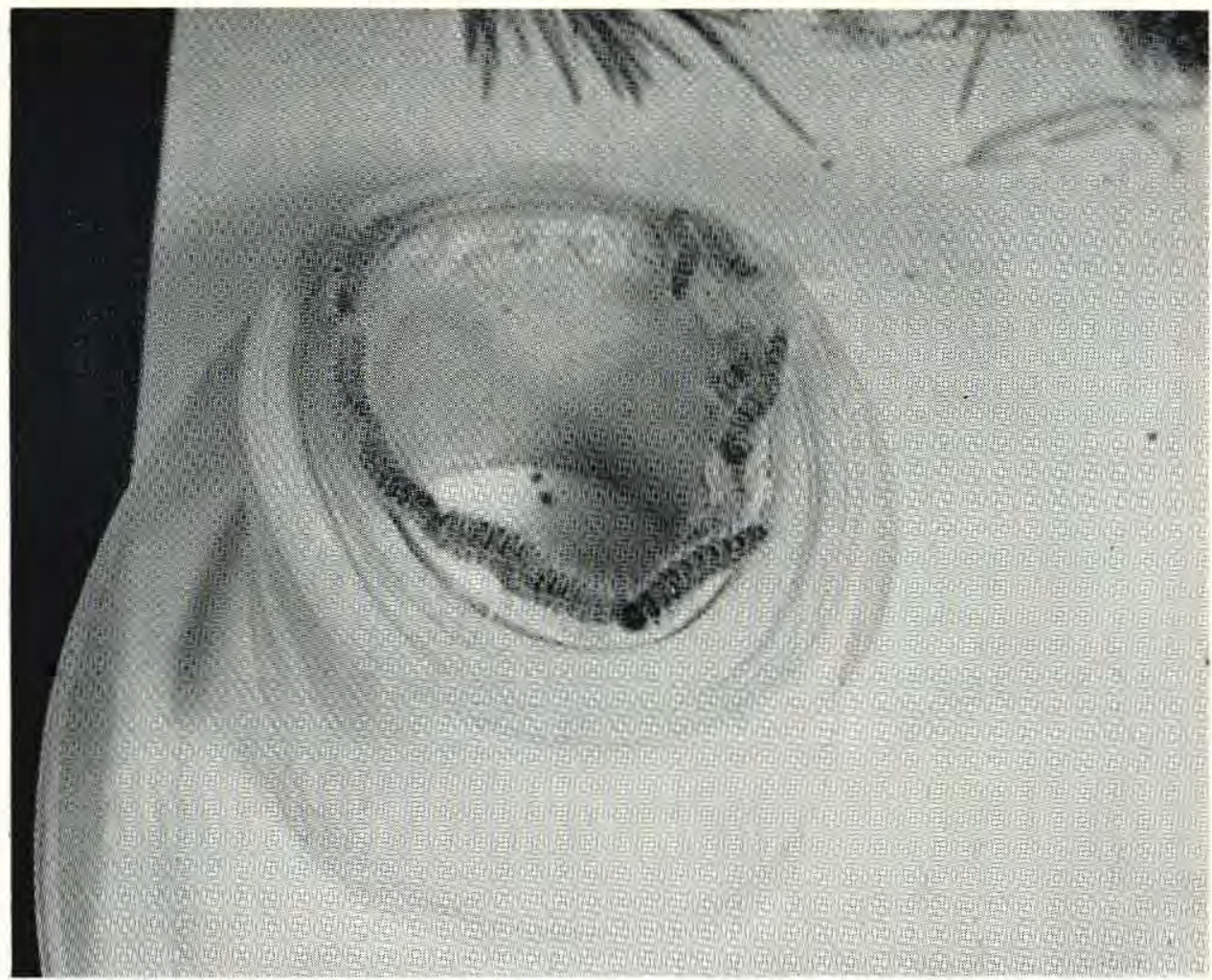

Fig. 3. Pine processionary caterpillars about to "form-up."

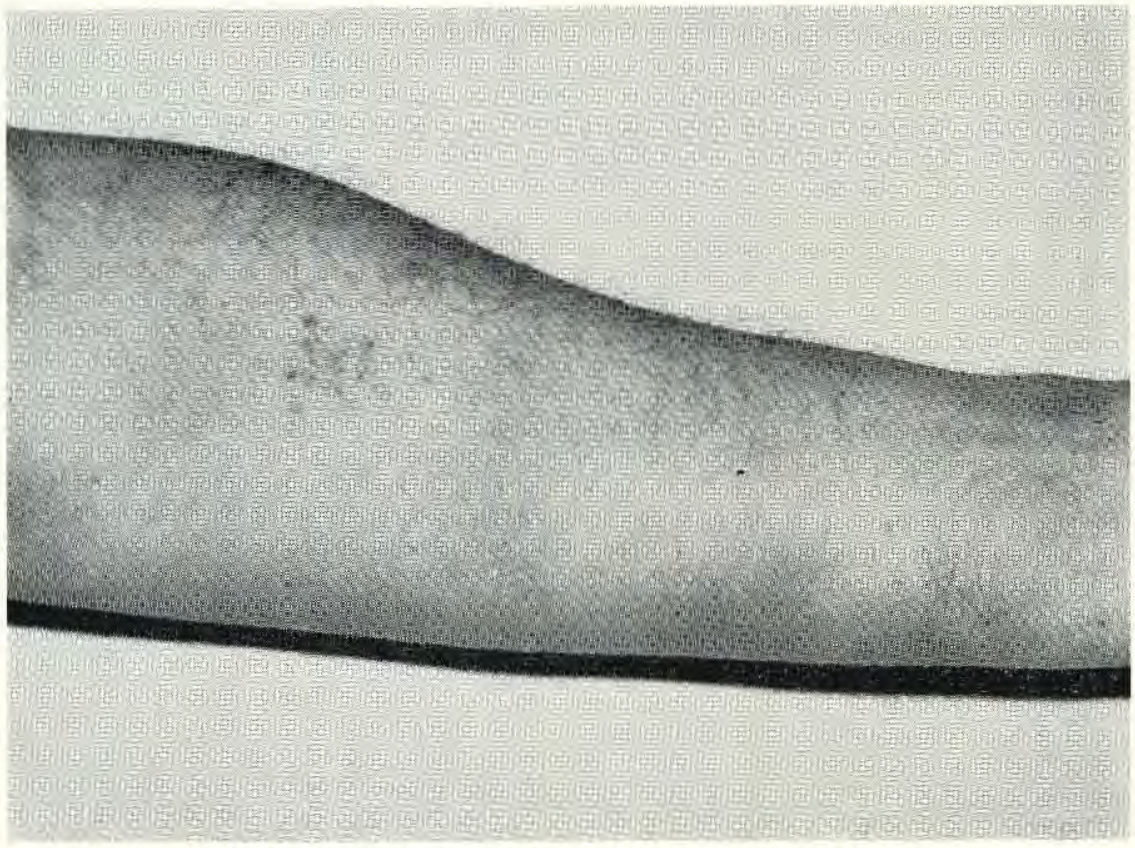

Fig. 4. Erythema from contact with disseminated hairs. 


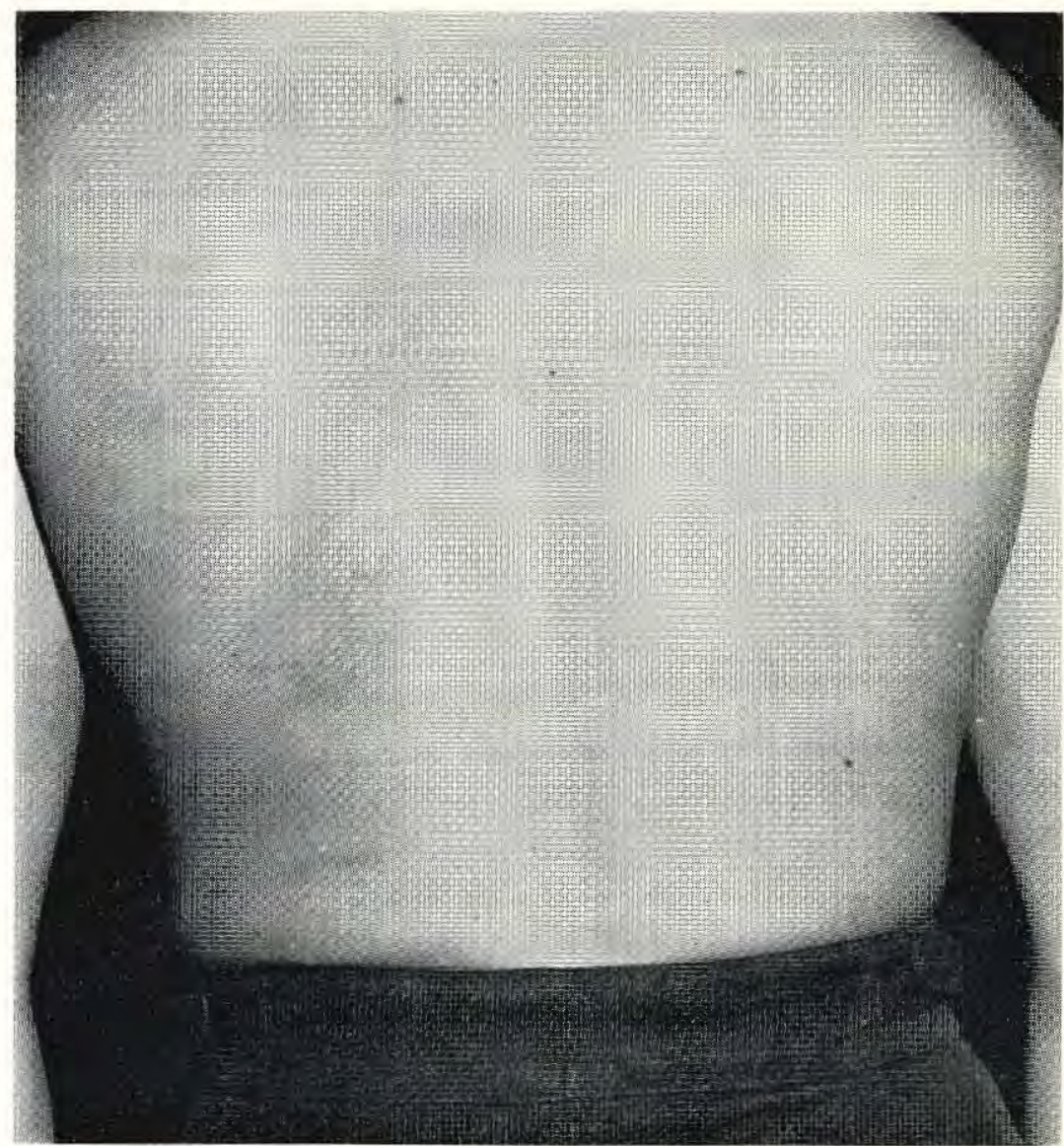

Fig. 5. Urticaria following contact with two caterpillars.

Fifteen minutes later there was erythema in the areas rubbed. This increased and the two red areas joined after thirty minutes. At this time urticaria was developing in the initial contact areas and this continued to increase in size until about one hour after contact. Super-improved on a spreading erythema patches of urticaria developed away from the original area and two hours from the start the rash had spread to cover the entire back. Care was taken to minimise the air-borne spread of hairs and it appeared that the total reaction was initiated by contact with the two small areas of skin.

One hour after rubbing when the left side was extensively covered the effect of local application was tried. The upper back and shoulder areas were covered in an aqueous calamine lotion, and the lower third and waist with 1 per cent hydrocortisone lotion. There were no changes detected in the size or the intensity of the lesions and the rash faded at the same rate in all areas. Apart from an intense desire to scratch there was no constitutional upset although the rash took five days to completely disappear.

\section{Discussion}

The nature of the urticating substance has attracted some interest. Cheverton (1936) recorded that hairs washed in ether and placed on the skin caused no irritation while the 
extract in ether did cause urticaria. Although it has some histamine like activity the active principle does not appear to be histamine but a protein of large molecular weight (Smith 1966).

Apart from the rather alarming reactions to the puss caterpillar (McMillan and Purcell 1964), caterpillar dermatitis produces little or no constitutional upset. This is perhaps some consolation since treatment, at least in the form of local applications, is not effective.

\section{Acknowledgements}

I am indebted to Mr. N. R. H. Burgess for his assistance and advice and to many individuals who developed urticaria, some innocently, some otherwise, in Cyprus during 1969.

\section{REFERENCES}

Cheverton, R. L. (1936). Trans. roy. Soc. trop. Med. Hyg. 29, 555.

Davis, R. A. (1947). Proc. roy. ent. Soc. Lond. 22, 3.

Hellier, F. F. and WARIN, R. P. (1967). Brit. med. J. ii, 346.

Herms, W. B. and JAMES, W. B. (1961). Medical Entomology. Fifth ed. Collier-McMillan Ltd. London. Page 539.

McMillan, C. W. and Purcell, W. R. (1964) New Engl. J. Med. 271, 147.

SMITH, W. D. L. (1966). Practitioner 196, 690. 